\title{
Excited states of plasmas for steel surface nitriding and $\mathrm{T}_{\mathrm{i}} \mathrm{N}$ deposition
}

\author{
A.Ricard ${ }^{*}$, G.Henrion, H.Michel, M.Gantois \\ * Laboratoire PGP Bt 212 - CNRS-UA 073, Université Paris-Sud 91405 Orsay, \\ France. \\ Lab.Génie Métallurgique - CNRS UA 159, Ecole des Mines, 54042 Nancy, France

\begin{abstract}
The excited states of plasmas for surface treatments have been detected by emission and absorption spectroscopy. For steel nitriding, the absorption spectroscopy using a dye laser (CARS) has given the vibrational $\mathbb{N}_{2}(\mathrm{X}, \mathrm{V})$ densities which are the most relevant species with $\mathbb{N}$ atoms and $\mathrm{N}_{2}+$ ions. For $\mathrm{T}_{i} \mathbb{N}$ deposition, the emission spectroscopy has given the best working conditions of the hollow cathode discharge presently used.
\end{abstract}

\section{INTRODUCTION}

Low pressure discharges are commonly used for surface coatings as steel nitriding (ref. 1) and $T_{i} N$ deposition on metals (ref. 2). Although plasma nitriding is nowadays widely used commercially and many of the metallurgical problems solved, there are still unanswered questions about the glow discharge, for instance the active species are not well known. It is the purpose of the present work to analyse the glow discharge by emission and absorption spectroscopy in operating conditions of plasma nitriding and plasma deposition of $\mathrm{T}_{i} \mathrm{~N}$ on steel surfaces.

\section{EXCITED STATES OF PLASMAS FOR STEEL SURFACE NITRIDING}

A typical reactor is shown in Fig. 1. It has been described in detail elsewhere (ref. 3). A flowing $\mathrm{N}_{2}-\mathrm{H}_{2}$ plasma was performed between the metal surface to nitride which is the cathode $(K)$ and the reactor walls which are the anode (A) at the ground potential. The plasma fulfills the two functions of to heat the metal surface by ions bombardment and to create the active species for the metal surface nitriding. The light emitted by the plasma is detected through a hole (0) in the plasma reactor by using a Jobin-Yvon monochromator (resolution limit $\delta \lambda=0.2 \AA$ ).

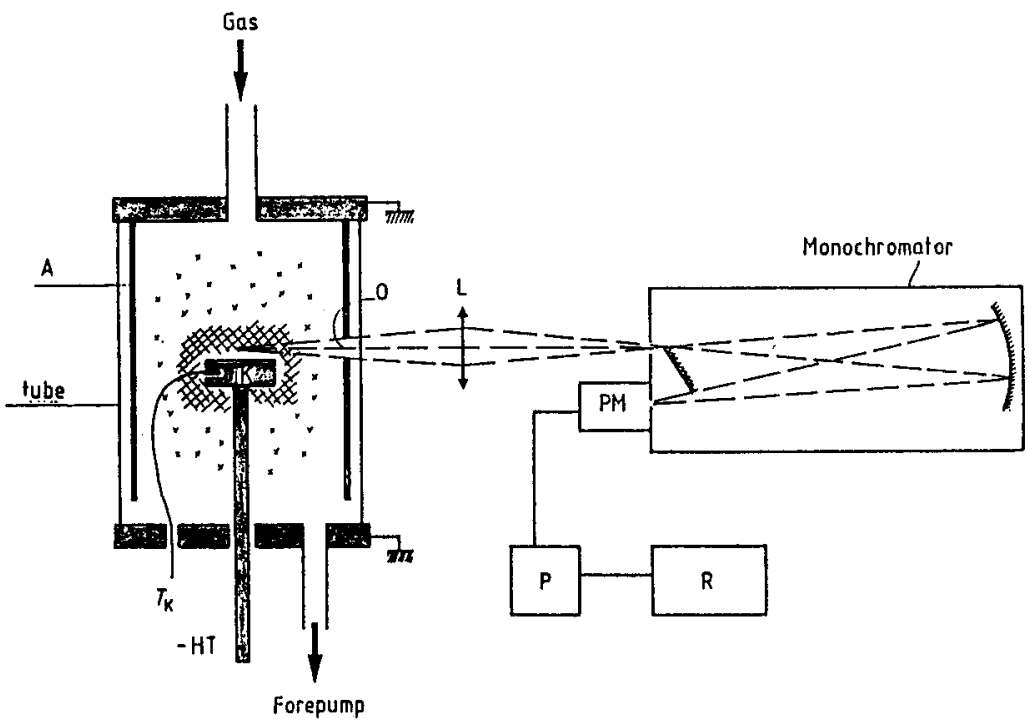

Fig. 1. Experimental set-up for steel surface nitriding : A anode, K Steel cathode (dia. $3 \mathrm{~cm}$, surface $20 \mathrm{~cm} 2$ ), 0 hole $(d i a .1 \mathrm{~cm}$ ) and pinholes (dia. 2mm), I optical lens, PM photomultiplier, $F$ picoammeter, R, recorder. Gas flow $1-5 \ell h^{-1}$ STP, $P=1-5$ Torr. 


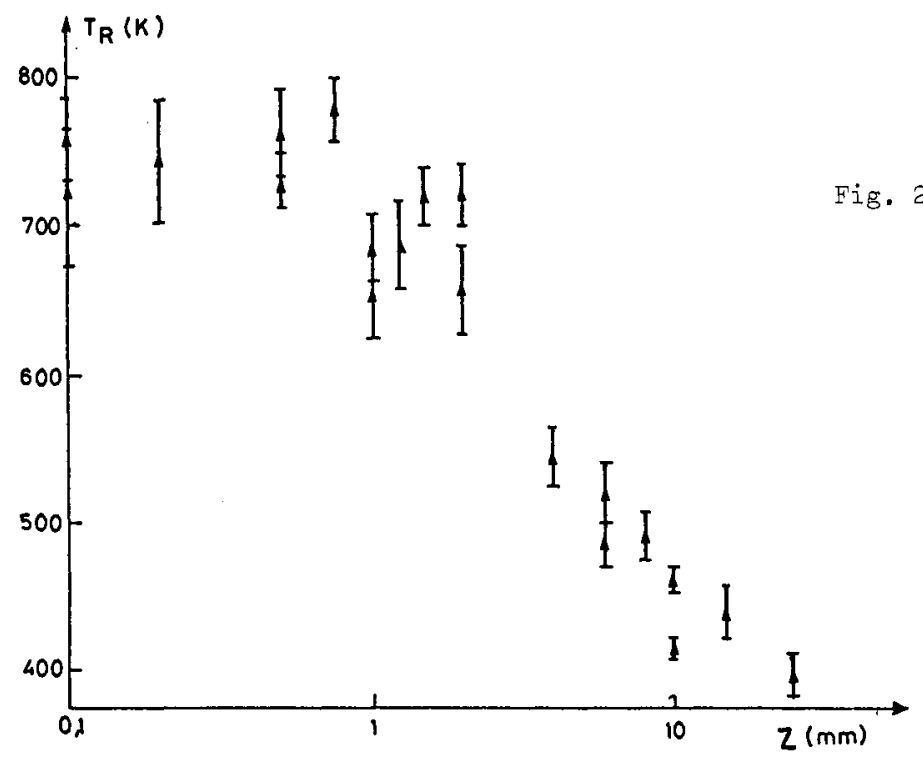

The excited states of $\mathrm{N}_{2}{ }^{+}, \mathrm{N}_{2}, \mathrm{NH}, \mathrm{H}, \mathrm{N}, \mathrm{N}^{+}$and $\mathrm{F}_{\mathrm{e}}$ have been detected ( $r$ ef. 3). The $\mathrm{N}_{2}{ }^{+}$emission (1st negative) was found to be the most intense in $\mathrm{N}_{2}$ and $\mathrm{N}_{2}-\mathrm{H}_{2}$ mixtures at pressure of 2-3 Torr and current density of about $5 \mathrm{~mA} \mathrm{~cm}-2$. The rotational structure of the $\mathrm{N}_{2}^{+}$, 1st negative $\mathrm{R}$-branch, has been recorded and $\mathrm{N}_{2}^{+}$rotational temperature $\left(\mathrm{T}_{2}+\right)$ has been calculated from the boltzman graph. In the negative glow near the cathode fall of the $\mathrm{N}_{2}-\mathrm{H}_{2}$ discharges, $\mathrm{TN}_{2}^{+}$has been found to be close (ref. 3) to the cathode temperature $\left(T_{K}\right)$ which has been measured with a thermocouple. Precise results on ground state $\mathbb{N}_{2}$ rotational temperature $\mathrm{T}_{R}$ have recently been obtained (ref. 4) by CARS analysis from the cathode fall to the negative glow of d.c. discharges. As show in Fig. 2 , it has been determined in a 2 Torr, $2 \mathrm{~mA} \mathrm{~cm}^{-2} \mathbb{N}_{2}$ discharge, $T_{R}$ values which are growing from about $400 \mathrm{~K}$ in the negative glow ( $\mathrm{Z}$ ) $5 \mathrm{~mm})$ to $750 \mathrm{~K}$ in the cathode fall $(\mathrm{z}=0.1-1 \mathrm{~mm})$. The $\mathrm{N}_{2}$ molecule heating in the cathode fall can be explained by charge transfers from $\mathrm{N}_{2}^{+}$ions.

Special attention has been devoted to the vibrational distribution of $N_{2}(x, V)$ ground state in the glow discharge. First the master equations for vibrational excitation coupled to be Boltzman equation for electron have been calculated by M. Capitelli et al (ref. 5). Second, the vibrational distribution has been measured in $\mathrm{N}_{2}$ positive column by CARS(ref, 4$)$. The $\mathbb{N}_{2}(\mathrm{X}, \mathrm{V})$ densities are given in Fig. 3 for $\mathrm{P}_{\mathrm{N}_{2}}=2$ Torr, $\mathrm{E} / \mathrm{n}_{\mathrm{O}}=5 \times 10^{-16} \mathrm{~V} \mathrm{~cm}-2, \mathrm{n}_{\mathrm{e}}=1.7 \times 10^{10} \mathrm{~cm}^{-3}, \mathrm{~T}_{\mathrm{g}}=550 \mathrm{~K}$ and residence time in the dis-
charge $\mathrm{t}=10^{-2} \mathrm{sec}$.

The calculated values are increasing with the residence time $\left(10^{-3}-10^{-2}\right.$ sec.). in the discharge and are well related to the experimental results. Densities as high than $10^{14} \mathrm{~cm}^{-3}$ for $\mathrm{N}_{2}(\mathrm{X}, \mathrm{V}=10)$ are reproduced in the $\mathrm{N}_{2}$ glow discharge. Such vibrational states are the most populated excited molecules as shown in Table 1, 103 to 105 higher in density that for $\mathrm{N}_{2}+$ ions and electrons.

The $\mathbb{N}$ atoms which are coupled to the final step of the vibrational distribution $\left(\mathrm{N}_{2}(\mathrm{~V}=46)+\mathrm{N}_{2} \rightleftharpoons \mathbb{N}+\mathbb{N}_{2}+\mathbb{N}_{2}\right)$ are also strongly populated in the glow discharge, in the order of $1 \%$ as detected by NO titration (ref. 6 ).

Table 1. Plasma parameters and densities of species in $\mathbb{N}_{2}$ positive column $(\mathrm{R}=1 \mathrm{~cm})$. (From experimental results obtained in the orsay LPGP).

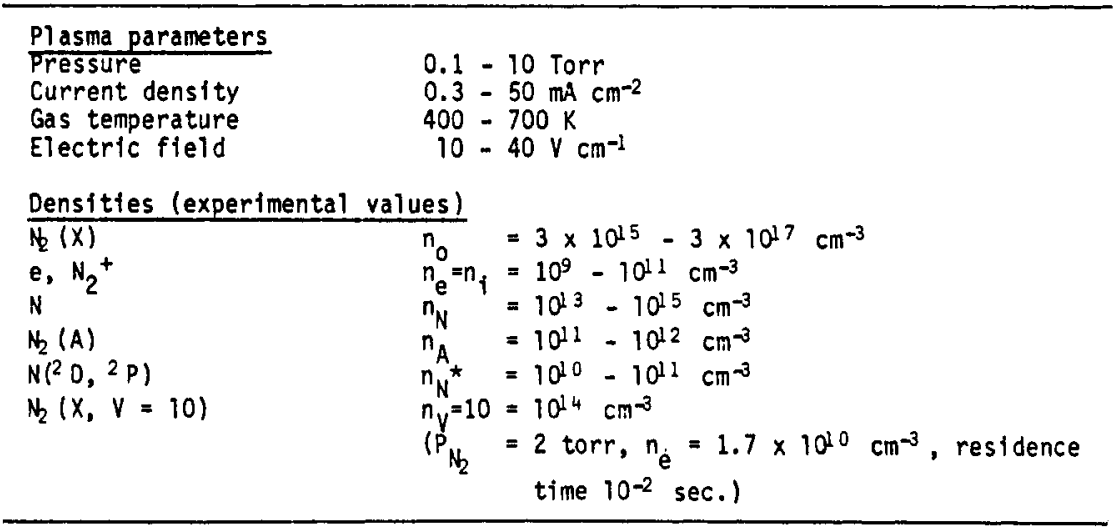




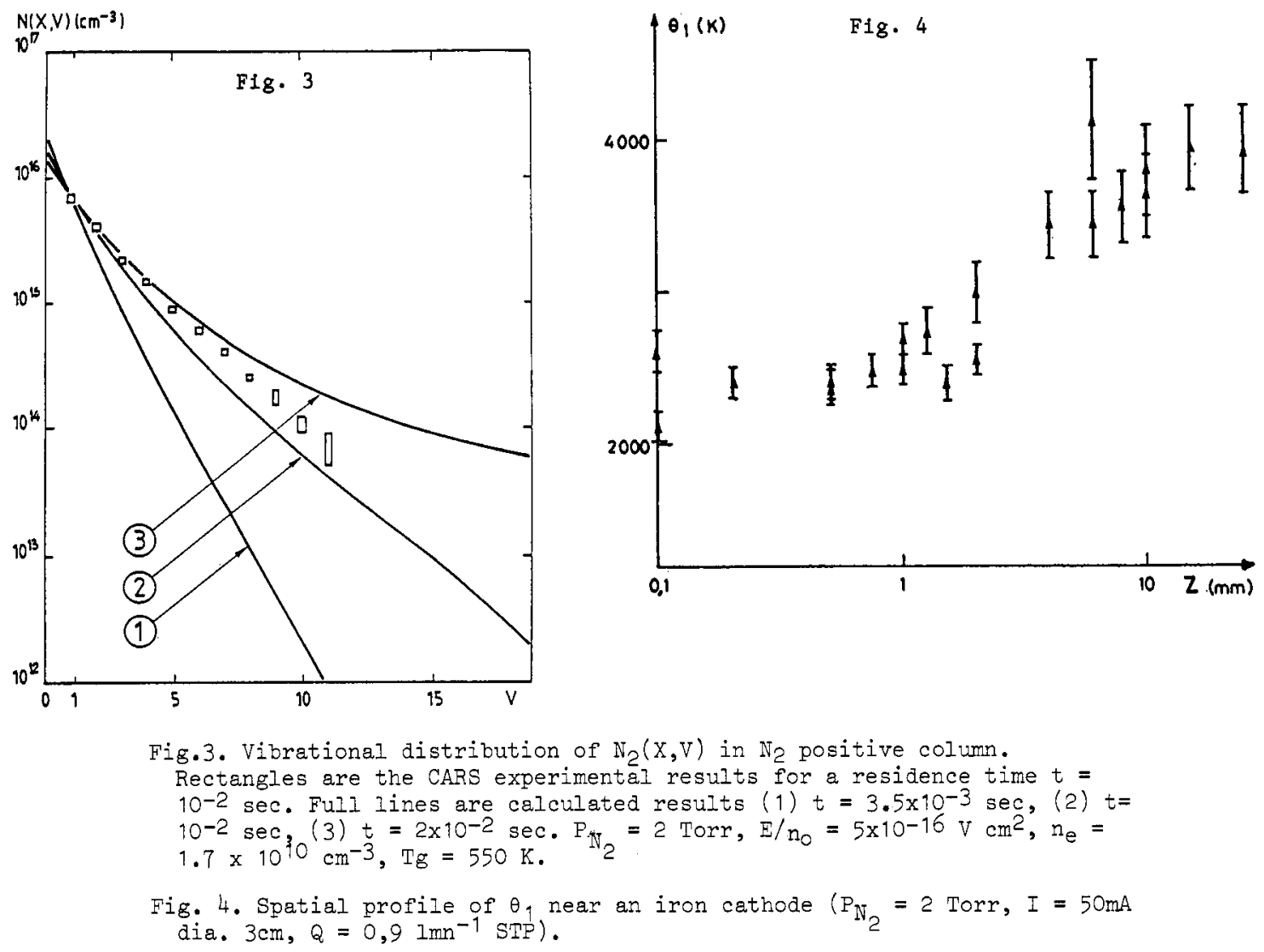

The characteristic vibrational temperature $\theta_{1}\left(\mathbb{N}_{2}(v=1) / \mathbb{N}_{2}(v=0)=\exp -\Delta E_{1}, 0 / k \theta_{1}\right)$ has been determined in the same conditionsas in Fig. 2 (ref. 4): As indicated in Fig. 4, the $\theta_{1}$-values are decreasing in the cathode fall from $4000 \mathrm{~K}$ in the negative glow to $2500 \mathrm{~K}$ near the cathode. The $\mathrm{T}_{R}$ and $\theta_{1}$ temperatures of $\mathrm{N}_{2}$ are varying in the opposite direction suggesting that the gas heating in the cathode fall increases the vibrational quenching of $\mathrm{N}_{2}(\mathrm{X}, \mathrm{V})$ molecules.

\section{EXCITED STATES OF PLASMAS FOR TiN DEPOSITION}

The excited states of $\mathrm{A}_{r}-\mathrm{N}_{2}-\mathrm{H}_{2}$ reactive sputtering plasmas used for $\mathrm{T}_{i} \mathrm{~N}$ deposition on steel substrates have been analysed by emission spectroscopy as shown in Fig. 5 . More details on the experimental set-up are given in ref. 7 . The plasma reactot is a stainless steel chamber, $45 \mathrm{~cm}$ in diameter and $90 \mathrm{~cm}$ high. As shown in Fig. 5 , a $\mathrm{T}_{i}$ emitter is located at the centre of the reactor. It is a circular array $(5.2 \mathrm{~cm}$ in diameter and $15 \mathrm{~cm}$ hihh) of eight $\mathrm{T}_{i}$ rods (dia. $1 \mathrm{~cm}$ ). A plain steel substrate was positioned at a distance $Z=16 \mathrm{~cm}$ from the $T_{i}$ cathode. A d.c. negative voltage $(-1500 \mathrm{~V}$ ) was applied to the cathode. The substrate was biased up to $-400 \mathrm{~V}$ (usually - 150V). The reactor wall was grounded. The discharge current was about $3 \mathrm{~A}$ on the cathode and $0.5 \mathrm{~A}$ on the substrate. Typically the gas mixture was $65 \% \mathrm{Ar}-32.5 \% \mathrm{H}_{2}-$ $2.5 \% \mathrm{~N}_{2}$ at a pressure of $10^{-1}$ Torr and a flow rate of $5 \mathrm{lh}^{-1}$ STP. The light emitted by the plasma was detected by the same optical arrangement as shown in Fig. 1. The optical system rested on a rotating table that allowed a spatial distribution study between the $T_{i}$ cathode $\left(K_{c}\right)$ and the substrate $(S)$.

The excited states of $\mathrm{T}_{i}, \mathrm{~T}_{i}^{+}, \mathrm{H}, \mathrm{N}_{2}^{+}, \mathrm{N}_{2}, \mathrm{~A}_{\mathrm{r}}$ and $\mathrm{A}_{\mathrm{r}}^{+}$have been detected. The spatial distribution of oexcited states are characterized by a nearly exponentially decreasing of $T_{i}$ atoms from the $\mathrm{T}_{i}$ cathode to the substrate and by a slow increasing of $\mathrm{N}_{2}$ with a maximum value near the substrate. This result has been correlated to the resulting coatings which vary from $T_{i 2} \mathbb{N}$ close to the $T_{i}$ emitter $(7 \mathrm{~cm})$ to $T_{i} \mathbb{N}$ further away (ref. 7).

A special effect of $\mathrm{H}_{2}$ had been observed in this reactive sputtering discharge. The spatial distributions of $\mathrm{A}_{r}^{+}, \mathrm{A}_{\mathrm{r}}, \mathrm{T}_{i}^{+}, \mathrm{T}_{i}$ and $\mathrm{H}$ excited states are given in $\mathrm{Fig}$. 6 from the hollow cathode center $\{\mathrm{z}=0\rangle$ to the substrate $(\mathrm{z}=120 \mathrm{~mm})$ in a $\mathrm{A}_{\mathrm{r}}-10 \% \mathrm{H}_{2}$ gas mixture at $p=0.1$ Torr. By cutting off the hydrogen gas feed and by outgasing the 


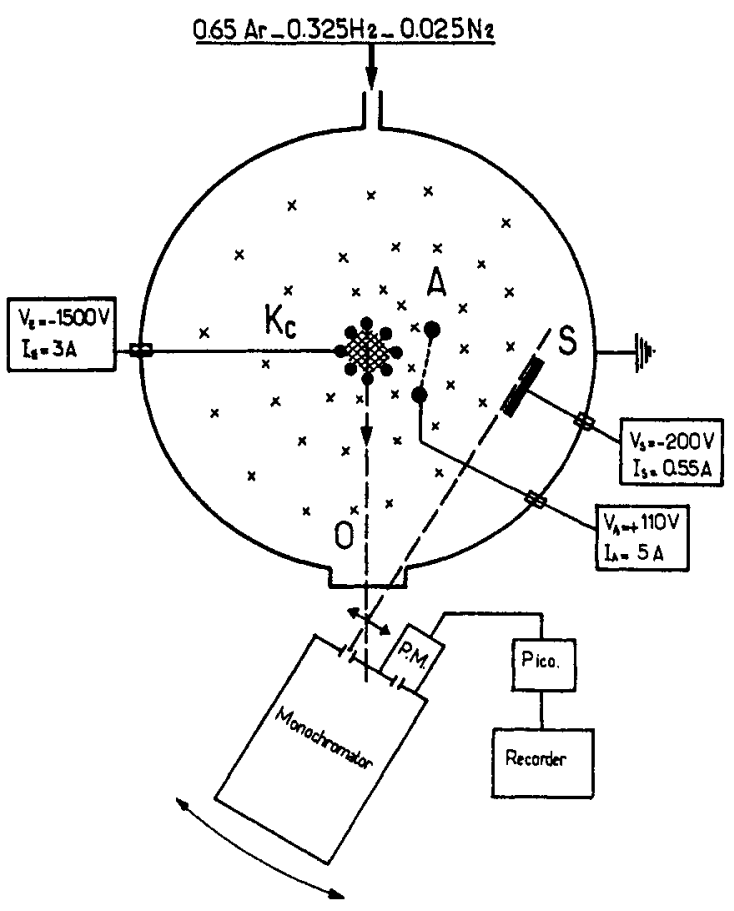

Fìg. 5. Experimental set-up of Ti hollow cathode discharge for titanium nitride deposition ( $\mathrm{p}=7.6 \times 10^{-2}$ Torr, flow rate $5-6 \mathrm{l}^{-1} \mathrm{STP}, \mathrm{K}_{\mathrm{c}}$ titanium emitter comprising an array of $8 \mathrm{Ti}$ rods (dia. $1 \mathrm{~cm}$ ), s steel substrate, A loop electrode, O Pyrex window.

substrate with a negative voltage up to 600 volts (ion bombarding), only a weak emission of hydrogen lines was observed from the $A_{r}$ plasma. Then by introduction gain $10 \%$ of $\mathrm{H}_{2}$ in $\mathrm{A}_{\mathrm{r}}$ it was observed the emission of excited species as shown in Fig. 7. A weak $\mathrm{H}$ emission an inversily strong $\mathrm{T}_{j}$ and $\mathrm{T}_{i}^{+}$emission were recorded during all the time when the discharge was running. Inside the $T_{i}$ cathode array, the $\mathrm{A}^{+}, \mathrm{T}_{i}{ }^{+}$and $\mathrm{T}_{i}$ excited state which are related to the pulverizing process were strong in intensity and the $F$ and $A_{r}$ emission disappeared (cf. Fig. 7). Such results were unchanged when $2 \%$ of $\mathrm{N}_{2}$ was introduced into the $\mathrm{A}_{r}-10 \% \mathrm{H}_{2}$ gas mixture and when the substrate was polarized or not.
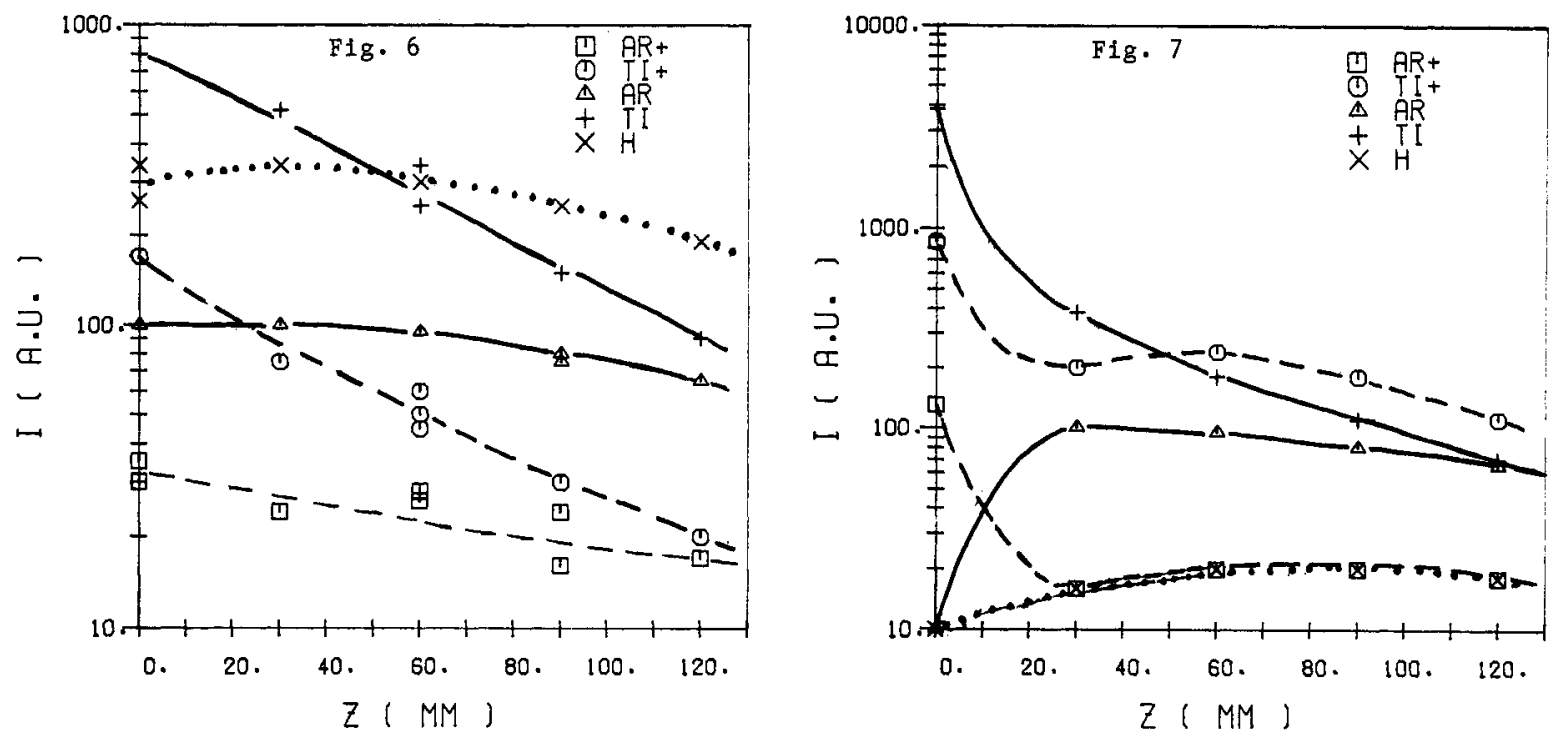

Fig. 6. Intensities (relative units) of $\mathrm{H}, \mathrm{T}_{\dot{i}}, \mathrm{~T}_{i}{ }^{+}, \mathrm{A}_{r}, \mathrm{~A}_{r}{ }^{+}$excited states from the hollow cathode center $(Z=0)$ to the substrate $(Z=120 \mathrm{~mm})$. A $A_{r}-10 \%$ $\mathrm{H}_{2}$ gas mixture, substrate not degasing by $\mathrm{A}_{r}$ ion pulverizing.

Fig. 7. Same radiative states as in Fig. 6. Substrate degasing by $A_{r}$ ion pulverizing and then introduction of $10 \% \mathrm{H}_{2}$ in $\mathrm{A}_{r}$ ( $\mathrm{p}=0.1$ Torr). 


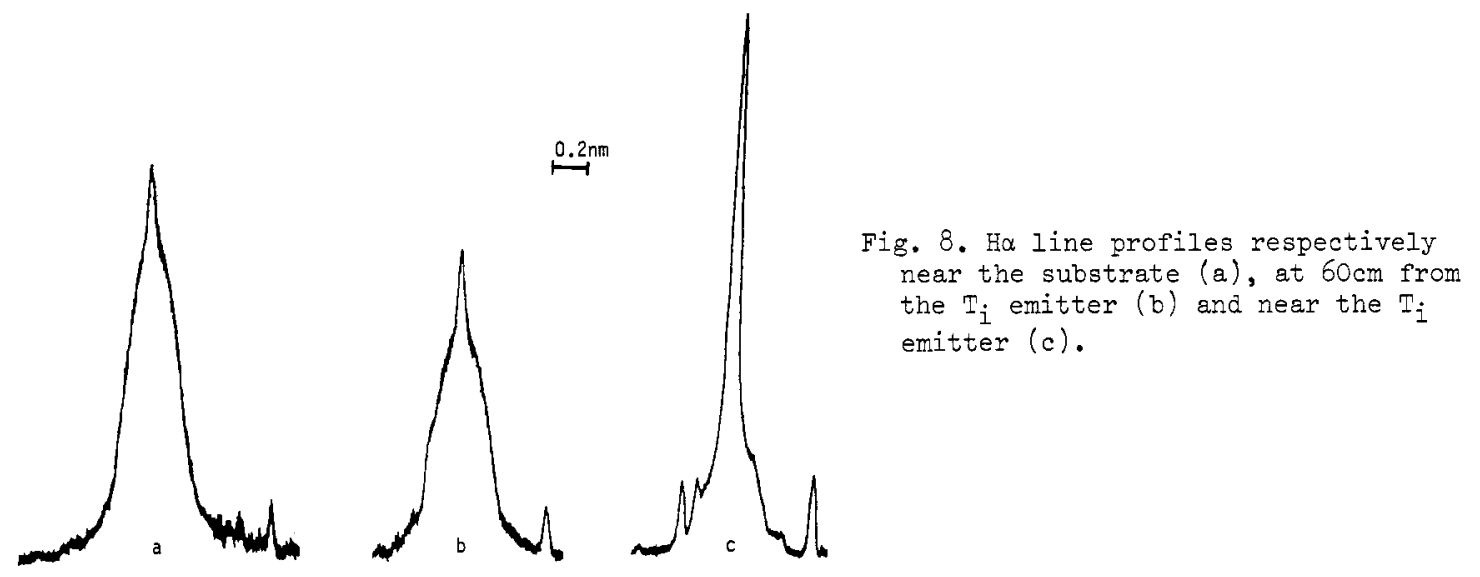

Profiles of $\mathrm{Ha}$ emission have been recorded from the $T_{i}$ emitter to the substrate (ref. 8). As shown in Fig. 8, surprising profiles have been recorded near the substrate (a), at $60 \mathrm{~cm}$ from the $T_{i}$ cathode (b) and near the cathode (c) in a $A_{r}-10 \%$ $\mathrm{N}_{2}$ mixture.

The profiles of $H \alpha$ consist of a narrow central peak of wiath equal to $0.05 \mathrm{~nm}$. which tops a very large and broad non gaussian component of width $\simeq 0.35 \mathrm{~nm}$. The narrow peak is the result of Doppler broadening of slow $H$ atoms with energies less than $1 \mathrm{ev}$. The broad component comes from fast $\mathrm{H}$ atoms whose energies are between 10 and $100 \mathrm{ev}$.

Such fast $\mathrm{H}$ atoms are produced by dissociative ionization of $\mathrm{H}_{2}$ following the reactions :

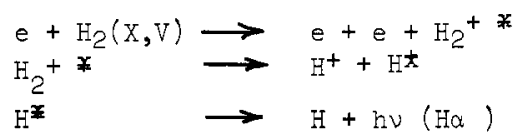

The broad component is dominant near the substrate (Fig. 8 a) when the $\mathrm{H}_{2}$ gas feed was cut off. Then the $H$ desorption from the substrate can produce $\mathrm{H}_{2}-$ which lead to vibrationally excited neutral molecules $H_{2}(X, V)$ (ref. 9 ) and to fast excited $H$ atoms following reactions 1 and 2 .

It appears from this study that the best working conditions of $T_{i}$ sputtering are obtained in pure $A_{r}$ discharge. The reactive $\mathrm{H}_{2}$ and $\mathrm{N}_{2}$ gases are necessary to obtain unpowdery $T_{i} N$ coatings but they must be introduced in such a manner that the $A_{r}-T_{i}$ plasma prevents the poisoning of the cathode and substrate metal bodies by these reactive gases.

\section{CONCLUDING REMARKS}

The spectroscopy of plasmas for surface treatments is an in situ diagnostics allowing to study the behaviour of the active species during a given process. For steel nitriding, the $\mathrm{N}_{2}{ }^{+}$ions and the $\mathrm{N}_{2}(\mathrm{X} . \mathrm{V})$ and $\mathrm{N}$ neutral species appear to be relevant species. The $\mathrm{H}_{2}$ gas is introduced into the nitriding plasmas presumebly to destroy the metal surface oxides and also to obtain unpowdery $T_{i} \mathbb{N}$ coatings. But caution must be taken with $\mathrm{H}_{2}$ in sputtering discharges since the cathode and the substrate could be poisened by this reactive gas perturbing the plasma working conditions.

Acknowledgements This work was supported in part by the DGA-DRET.

\section{REFERENCES}

1.J.P.Lebrun, H.Michel and M.Gantois. Mem.Sci.Rev.Metallurgie 69, 727 (1972).

2. H.Michel, M.Gantois and C.H. Luiten. Heat Treatment $84(1984)$

3. L.Petitjean and A.Ricard. J.Phys. D.17, 919 (1984).

4. Nolefebvre et al. ISPC 8 , Tokyo $(1987)$.

5. Non Equilibrium Vibrational Kinetics, Topics in Current Physics 39 (1986) Edit. M.Capitelli, Springer Verlag.

6. G.Cernogora. Thèse Orsay (1982)

7. A.Ricard, H.Michel, F.Jacquot and M.Gantois. Thin Solid Film 12467 (1985). J.Phys. D 181701 (1985)

8. G.Sultan et al. ISPC 8. Tokyo (1987).

9. J.W.Gadzuk. J.Chem.Phys. 793982 and 6341 (1983). J.W. Gadzuk and J.K.Norskov. J.Chem. Phys, 81 2828 (1984). 